\title{
Communicating bad news in the context of COVID-19
}

\author{
Edgar Landa-Ramírez ${ }^{1,2 *}$, Nadia A. Domínguez-Vieyra ${ }^{1,2}$, Myriam E. Hernández-Núñez $^{1,2}$, \\ Lesly P. Díaz-Vásquez ${ }^{1,3}$, and Filiberto Toledano-Toledano 4 \\ ${ }^{1}$ Programa de Psicología Urgencias, Hospital General Dr. Manuel Gea González, Mexico City, Mexico; ${ }^{2}$ Programa de Psicología de la Salud y

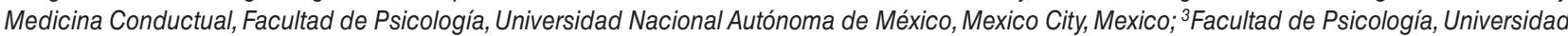 \\ Nacional Mayor de San Marcos, Lima, Peru; ${ }^{4}$ Unidad de Investigación en Medicina Basada en Evidencias, Hospital Infantil de México Federico \\ Gómez, Mexico City, Mexico
}

\begin{abstract}
Communicating bad news is one of the most frequent activities in hospitals, for which some recommendations have been adapted to the needs within the coronavirus-2 disease (COVID-19) context. This document presents nine steps to deliver bad news (face to face or remotely) adapted to the COVID-19 context from two international protocols (SPIKES and GRIEV_ING). The importance of promoting physical and emotional self-care skills in health personnel is also described, as well as psychological first aid strategies to address the emotional response of the family member who receives the news. Finally, the limitations and advantages of the proposal should be considered.
\end{abstract}

Key words: Communication of bad news. SPIKES. GRIEV_ING. Pandemics. COVID-19.

\section{Comunicación de malas noticias en el contexto de la COVID-19}

\section{Resumen}

La comunicación de malas noticias es una de las actividades más frecuentes en los hospitales dentro del contexto de la COVID-19. A pesar de su alta frecuencia, existen pocas recomendaciones adaptadas a las necesidades que el contexto de la COVID-19 demanda. Debido a lo anterior, en el presente escrito se presentan nueve pasos para dar malas noticias (cara a cara o por vía remota) de dos protocolos internacionales (SPIKES y GRIEV_ING) adaptados a las necesidades de transmisión de información de la COVID-19. Se describe también la importancia de promover habilidades de autocuidado físico y emocional en el personal de salud, así como estrategias de primeros auxilios psicológicos para el abordaje de la respuesta emocional del familiar que recibe la noticia. Finalmente, se deben considerar las limitaciones y ventajas de la propuesta.

Palabras clave: Comunicación de malas noticias. SPIKES. GRIEV_ING. Pandemias. COVID-19.

\section{Introduction}

The emergence of a new type of coronavirus disease at the end of 2019 (SARS-CoV-2) has produced multiple clinical care challenges for the medical sector. It is estimated that COVID-19 (coronavirus-2 disease) has infected nearly 9.5 million people worldwide and that almost 500,000 people have died, where Europe and the Americas have been the most affected regions ${ }^{1}$.

\section{Correspondence:}

*Edgar Landa-Ramírez

E-mail: edgar_landa_ramirez@yahoo.com.mx

1665-1146/@ 2020 Hospital Infantil de México Fed (http://creativecommons.org/licenses/by-nc-nd/4.0/).
Date of reception: $29-06-2020$

Date of acceptance: 08-07-2020

DOI: 10.24875/BMHIM.20000201
Available online: 24-02-2021

Bol Med Hosp Infant Mex. 2021;78(1):59-65 www.bmhim.com 
Over 250,000 cases have been confirmed to the present date, and more than 25,000 deaths have been recorded in Mexico ${ }^{2}$. It is projected that the number of infected people and deaths will continue to rise significantly. In the context of the COVID-19 scenario, bad news communication is and will remain highly frequent.

The concept of bad news refers to any information that is likely to radically and negatively alter a person's view of their future: plans change and expectations are limited, and anything that was not accomplished now seems impossible to achieve ${ }^{3}$. The grade of bad news depends on several internal and external factors to the individual who receives it, such as the stage of life, the physical and emotional state, beliefs, personality, culture, and specific characteristics of the news itself, including sudden and unexpected events ${ }^{4,5}$. However, within the hospital context, there is some news that, given their nature, are more likely to be considered "bad news": a new diagnosis, a bad prognosis, the application of certain invasive procedures, or the death of a beloved one ${ }^{6}$.

Although communicating bad news is a common task for medical personnel, they receive very little formal training to execute it, which results in behaviors cataloged by patients and families as impersonal, unsympathetic, hurried, and the transmission of technical or ambiguous information. Consequently, these behaviors are associated with adverse psychological effects in the short and medium-term on patients and relatives who receive the bad news and the health personnel who transmit the information ${ }^{6}$.

International research suggest that solutions to these problems have been sought by creating training programs that aim to improve medical information transmission. Two training protocols have been proposed. First, the SPIKES protocol ${ }^{7}$, which is based on six steps proposed by Buckman and Kason at the Johns Hopkins University ${ }^{8}$ and was later developed in the field of oncology to improve the communication of new diagnoses and poor prognoses. Second, the GRIEV_ING ${ }^{9}$ protocol, which was created for sudden-breaking death notifications within the medical emergencies field. A systematic review has reported that health-care personnel's training programs in communicating bad news, primarily those based on the SPIKES protocol, enhance bad news communication skills, and medical staff confidence $^{10}$. Another recent systematic review on programs of death notifications in medical emergencies suggests improved bad news communication when the GRIEV_ING program is applied to transmit this type of information ${ }^{11}$. Furthermore, other studies have reported a higher level of empathy in physicians when communicating the news ${ }^{12}$. One study reported that this type of training might decrease negative responses (e.g., shock or anger) from family members when receiving the news ${ }^{13}$.

In general, bad news delivery protocols share the following procedures: encourage the privacy of notification, identify the level of knowledge of the patient or family member before receiving the news, provide information about the news in a comprehensive manner, promote respect for the emotional response of the family member receiving the news, and specify the procedure to be followed once the news is completed ${ }^{7,9}$. Despite their usefulness, it does not seem viable to apply these protocols to the COVID-19 context because they were initially intended to be used in situations triggered by chronic diseases or sudden events. Therefore, both protocols mentioned earlier encourage actions such as sharing physical spaces with one or more family members where the news will be transmitted, physical closeness for empathy, and entering the hospital to farewell the deceased patient's body. Furthermore, they assume the investment of much time to transmit the information, which is not viable due to health-care personnel's high workload during the current situation.

Recent international literature has pointed out the importance of generating recommendations adapted to bad news communication in the current circumstances considering the usual protocols' limitations. The recommendations developed so far range from general principles based on evidence (such as preparing oneself and the environment, promoting that the person is accompanied, transmitting clear information, respecting emotional responses of the family, and ending the meeting ${ }^{14}$ ) to the communication using telemedicine and the challenges involved in remote communication $^{15}$. Furthermore, there has been a compilation of opinions from experts regarding giving news remotely (video call or telephone) that highlights privacy, speaking clearly, and providing the news in a simple, honest, and empathetic way ${ }^{16}$.

These recommendations constitute a step forward in communicating bad news. However, we need to consider this pandemic's characteristic elements. To more accurately cover the characteristics of bad news communication in the context of COVID-19, the authors reviewed scientific articles in Medline/PubMed that describe these characteristics and examined international and national journalistic reports on the subject. Similarly, an interview was conducted with health-care 
personnel in Italy (during the peak of its pandemic) and medical personnel in charge of coordinating the COVID-19 area at the Hospital General Dr. Manuel Gea González in Mexico City.

Based on the information obtained, it became essential to identify each region's context, needs, conditions, and statutes in which the news is transmitted. For example, should the communication of bad news be carried out in person or remotely? This answer would imply taking different measures in each case, such as using personal protection equipment or cleaning remote technological devices. Furthermore, the documents previously outlined do not adequately consider the emotional stress that doctors are experiencing, which is coupled with communicating bad news and dealing with the emotional response of the family member who receives it. Therefore, recommendations are needed to encourage doctors' self-care before and after facing this difficult task, described as a frequent and strenuous activity ${ }^{17-19}$.

In the current situation under COVID-19, it is essential to consider cultural nuances since each region establishes the official management of dead bodies. On the one hand, family members often have no possibility of performing the usual funeral rituals, which will add a significant emotional burden. On the other hand, the emotional responses that family members may display to bad news will always be influenced by their particular context and are therefore unpredictable. Moreover, none of the writings mentioned above provide specific suggestions about how to be empathetic or what health-care staff can do if the emotional response of the person receiving the news is exacerbated. It is also worth mentioning that the documents resume or provide general suggestions without a specific structure of the steps or behaviors to be performed, generating ambiguity.

Therefore, it is essential to propose a protocol that considers useful recommendations that have been proven and a description of the conduct that entails this protocol. In addition, it considers the particularities of the COVID-19 context. Consequently, we present a protocol for the empathic communication of bad news in the context of COVID-19, adapting the SPIKES ${ }^{7}$ and GRIEV_ING ${ }^{9}$ protocols recommendations to the current situation needs.

\section{Protocol for the communication of bad news in the context of COVID-19}

This protocol consists of four categories: preparation, notification, closure, and self-care, in nine steps
(Table 1), which can be adapted to communicate the news in person (within the hospital) or remotely (telephone or video call). This protocol seeks empathic communication of bad news together with physical and emotional self-care in the health-care personnel transmitting the information.

1. Preparation

The aim is to generate the ideal conditions to transmit the information in a context of privacy, tranquility, and respect. Actions are also generated to promote the exchange of information about the patient, identifying the knowledge that the family member possesses. Finally, the objective of healthcare personnel is to develop physical and emotional care skills. The steps suggested are the following:

a) Find a private or quiet space to give the news. In the case of remote communication, make sure there is a good internet connection or phone signal. It is important to review the most relevant information of the case in the medical record. Before initiating contact, staff must follow the World Health Organization $(\mathrm{WHO})^{20}$ and Centers for Disease Control and Prevention (CDC $)^{21}$ guidelines for sanitation and physical safety actions (e.g., keeping a safe distance, using protective equipment, and cleaning the work area, especially telephones or computer equipment) ${ }^{20,21}$. Similarly, relaxation techniques such as diaphragmatic breathing can be followed for stress management ${ }^{22}$.

b) When initiating contact with the family member and if conditions are appropriate, it is recommended that the family member receiving the information be given the option of being accompanied by a close relative (following WHO and CDC biosecurity recommendations). When beginning, healthcare personnel must introduce themselves and indicate their role in the care of the patient.

c) To identify the most relevant information of the family member, the physician should ask about general data (age, occupation, educational level, and relationship with the patient), along with risk factors such as chronic health problems, mental health problems (especially depression, substance use, and suicide risk), and also the information that the family member has regarding the health status of the patient. It is important that the physician hears the relative's discourse. Even if the family member provides incorrect data, he or she should not be corrected.

2. Notification

The chronology of events should be taken from the family member. Then, clearly transmit the bad news, 
Table 1. Protocol for empathic communication of bad news in the context of COVID-19

Steps

1. Before making contact, gather case information, find a private place, and perform physical and emotional care actions

2. Offer the family member or patient to be accompanied and be sure to introduce yourself

3. Ask what information the family member has regarding the patient's health status

4. Resume the chronology of events and information that led to the patient's death from where the relative's story ended

5. Use preparatory phrases such as "I am sorry to inform you that" and then clearly state that the person died

6. Give a moment to express the family member's emotional response. Use empathic phrases and provide psychological first aid if necessary

7. Instructs the family member what procedure to follow, when they will receive more information, funeral arrangements, or local postmortem requirements, and the importance of monitoring possible COVID-19 symptoms
1.1. Look for a private and quiet place

1.2. If the meeting is remote, make sure to have a good telephone or internet connection

1.3. Clean the electronic devices used for the meeting, such as cell phone, telephone, computer, or tablet

1.4. Review the case and contact details in the medical record

1.5. Use relaxation techniques (e.g., diaphragmatic breathing) to regulate your stress

2.1. If possible, offer the family member to be accompanied by a close relative

2.2. Speak slowly, clearly, and calmly

2.3. Introduce yourself: "Hi, I am Dr. — say your name. I am part of the — say the name of your institution - report notification team. I am speaking to you to provide information about say the name of the patient. Can I speak to - say the name of the contact family member?

2.4. Ask the family member if they would like to be accompanied

3.1. If possible, obtain socio-demographic information on the family member: age, educational level, family relationship, physical illness, or mental health problems such as depression, substance use, suicide risk, and treatment adherence. This information will help you identify possible risks when faced with the news

3.2. Use open-ended questions about what they think about their patient's health status: what do they know? what have they been told? what does that mean?

3.3. Even if the family member provides incorrect data, do not correct it; listen and write it down

4.1. Go back to the chronology of events: "As you said, Mr/Mrs - say the name of the family member - we received Mr/Mrs - say the name of the patient - under these conditions - describe the conditions without using technical terms. We did these procedures describe the procedures (do not use technical terms)

4.2. Do not give the news of death yet!

5.1. Give the news in an empathic way. Try to understand the relatives' thoughts and emotions from their point of reference

5.2. Offer a preparatory phrase: $\mathrm{Mr} / \mathrm{Mrs}$ - say the name of the family member - "I am sorry to inform you that" (or "I would like to give you better news"); then clearly express that the person's health condition - say the name of the patient - "deteriorated seriously," or that "the patient died"

5.3. Do not use euphemisms, such as "is no longer with us". Be clear and use the words "dead" or "died."

5.4. If any, highlight procedures that helped to relieve pain or suffering in the patient

6.1. For empathic phrases, be genuine in the answers you express, generate trust, partner with the family member, and do not make value judgments

6.2. Name and validate the emotions presented by the family member: Relative: "You are incompetent; I will sue you!" Healthcare personnel: "I hear that you are very angry about the way things are going; it is understandable to feel this way; I will be supporting you with your doubts."

6.3. Make an effort to "read between the lines" to respond to the family member about what they are experiencing:

Relative: "My God, why is this happening to us!"

Healthcare personnel: "Without a doubt, these types of sudden events take us by surprise. Take your time. I will be here with you."

6.4. To provide psychological first aid: evaluate possible risks in the family member (observe), ask about concerns and needs (listen), and help the family member resolve those needs - or connect with people who can resolve (connect)

6.5. If the patient goes into crisis or shock, use a directive tone of voice and give instructions that will help restore functionality, such as clenching and stretching fists or placing feet firmly on the floor. Connect the family member to a specialized mental health support group

6.6. If the call is missed, make every attempt to return the call

7.1. In the event of a poor prognosis, tell the family member when they will receive reports again

7.2. In case of death, tell the family member what steps to take and empathetically inform the local regulations for the management of the deceased patient

7.3. If it is not feasible to carry out funeral rituals, be empathetic when transmitting this information

7.4. Encourage the family member to remain in quarantine and monitor COVID-19 associated symptoms in themselves and other family members who were in contact with the patient 
Table 1. Protocol for empathic communication of bad news in the context of COVID-19 (Continued)

\begin{tabular}{l|l} 
Steps & Recommendations or examples
\end{tabular}

8. Answer questions and offer the 8.1. Verify that there are no questions; if so, answer them referral for physical, social, or $\quad$ 8.2. If possible, provide a number for future inquiries mental health support in your $\quad 8.3$. Have local numbers available for physical, social, and mental health support local health system

9). At the end of the call, seek basic biosafety measures, and check your emotional state

9.1. Wash your hands and clean the devices used

9.2. Use relaxation techniques (e.g., diaphragmatic breathing) to regulate your stress

9.3. Seek support from a specialized mental health group if needed

showing respect for their dignity. According to the WHO recommendations, it is encouraged to give the family members space to respond and to provide emotional support or psychological first aid (observe, listen, and connect $)^{23}$ if necessary. The recommended steps are as follows:

d) From where the relative's story ended, the doctor must resume the chronology of events that led to the decline of the patient's health or death without communicating the news yet.

e) Preparatory phrases are suggested, such as "I am sorry to inform you that" or "I would like to give you better news," and then clearly state that "the person's health condition worsened" or "seriously deteriorated." If it is the case, indicate that the person "died." It is recommended to avoid or to clarify technicalities if necessary. It is also important not to use euphemisms such as "is no longer with us" or "has left." It is also suggested to highlight any procedures that helped relieve the patient's pain or suffering.

f) It is vital to give the family members a moment to express their emotional response, allowing silences, validating their emotions, and expressing brief empathic and genuine phrases (Table 1). Besides giving the WHO recommendations on psychological first aid, the principles recommended by the International Federation of Red Cross and Red Crescent Societies $^{24}$ can be followed in the case of a telephone call: assess possible risks, inquire, and help to resolve the family member's concerns, or connect family members with their support network or care services that can help to resolve the concerns. If the family member experiences an emotional crisis, it is necessary to use a directive tone of voice and give instructions to redirect the family member's attention and help them recover functionality. For example, a relaxation technique-such as diaphragmatic breathing-or directions for clenching and stretching fists or placing feet firmly on the ground ${ }^{24}$ can be promoted. In these cases, it is advisable to link the family member to a specialized mental health support group before ending the meeting. During the phone calls, it is important to consider that the voice will be the only tool to transmit warmth and empathy or be directive.

Sometimes individuals who receive bad news can react hostilely or aggressively against healthcare personnel and, considering the attacks against these professionals during the health emergency by COVID-19, it is crucial to take immediate and effective action. While scientific evidence requires more solid research to provide more reliable responses, the multisectoral participation of government entities, health institutions, and the population is suggested as preventive actions to support violence-free environments. Moreover, providing training to professionals on how to manage conflict and be aware of potential danger ${ }^{25}$.

Some recommendations outlined are the following ${ }^{26,27}$ : (1) be aware of signs of threat expressed physically or verbally, as well as the use of addictive substances or the carrying of weapons; (2) remain calm and display behaviors that help reduce or eliminate anger; (3) be alert during the interaction with patients or visitors if there are signs of a possible act of aggression, considering the support of other colleagues and always planning to have an evacuation route if necessary; and (4) if the personnel is unable to resolve the conflict quickly, it is best to walk away from the situation, ask for assistance from security personnel, and report any incidents to the appropriate hospital or clinic management.

3. Closing

The purpose is to provide information regarding subsequent procedures once the bad news has been given. It also provides recommendations for monitoring possible COVID-19 symptoms to the family member, clarifies any doubts, and offers referrals to 
physical, social, or mental health support if necessary. The recommended steps are as follows:

g) Emphatically, the doctor should inform the family member about the procedure to be followed. For example, how long it will take for them to have more information, or what they should do to begin the corresponding funeral arrangements, and indications about the local process for handling the body of the deceased. Since the family member has likely been in contact with the COVID-19 patient, it is vital to emphasize the importance of monitoring the disease's symptoms in the family member or other relatives close to the patient the last few days.

h) It is recommended to verify that there are no questions and, if necessary, resolve them. If possible, a telephone number can be provided for the attention of future doubts. It is also suggested to have local telephone numbers available for physical, social, and mental health support where the family member can be referred to if required.

4. Self-care of healthcare personnel

Physical and emotional care is promoted in the healthcare personnel once the meeting has ended.

i) It is essential to provide basic biosafety measures through hand washing and, if necessary, cleaning and sanitizing the technological devices of remote communication that has been used for telecommunication. Furthermore, the physician's stress levels should be regulated using some relaxation techniques, such as diaphragmatic breathing. It is vital to continually monitor self-emotional state so that, if required, support with a specialized mental health group can be sought (Table 1).

\section{Final considerations}

This paper is an effort to adapt international evidence-based recommendations ${ }^{7,9}$ to communicate bad news in the context of COVID-19. As authors, we consider the protocol to be a useful tool because it presents concretely and systematically the steps and phrases that can be clinically useful for health-care personnel on the front line of communicating bad news.

Despite the authors' initial enthusiasm, several limitations should be taken into account when applying this proposal. It should be considered that this protocol does not have any research data to support or refute its effectiveness, which is extremely important for evidence-based decision making. However, this problem is not exclusive; so far and due to the urgency that COVID-19 has brought to health-care personnel, all published recommendations on how to give bad news have resorted to clinical experience to guide the physician's actions ${ }^{15,16}$. As a next step, it is essential to generate robust knowledge in the area.

Although the steps were adapted from two effective international programs in bad news communication (SPIKES and GRIEV_ING) ${ }^{7,9-11}$, a second limitation is a heterogeneity in the number of steps that these protocols recommend, as well as in the way by which the effects should be evaluated (direct observations, self-reports, and Likert-type scales $)^{10}$. Despite this heterogeneity (SPIKES requests 17 steps $^{28}$; and GRIEV_ING, 27 steps ${ }^{9}$ ), both protocols share principles (promoting privacy, investigating the patient's or family member's perception before transmitting the news, empathic communication without euphemisms, respect for the emotional response, closing the notification process, and time dedication to the task) that allow the identification of a core process in the transmission of bad news.

As in others, health-care personnel must invest time in training and master this protocol's suggested components. This preparation may be complicated due to the heavy clinical or emotional workload of healthcare workers during a pandemic ${ }^{18,19}$, the amount of reading that should be done to keep up with patient management, or a lack of interest in recognizing the importance of the topic. To lessen the above issues' impact, we designed this protocol to have the minimum response requirement regarding the time and steps health-care personnel need to follow. For this reason, a toll-free distance learning course on this topic was created. In this course, information is given to healthcare personnel through videos on carrying out the steps. Furthermore, the course offers the possibility of giving the bad news in a fictitious clinical case. If requested, role-playing with professional actresses can be carried out to develop personal skills in communicating bad news ${ }^{29}$.

Finally, the communication of bad news in the context of COVID-19 is one of the activities carried out the most and that, in contrast, has the fewest recommendations. Future efforts will have to be directed towards generating data to develop guidelines on delivering bad news using face-to-face or remote communication, always respecting the person's dignity.

\section{Ethical disclosures}

Protection of human and animal subjects. The authors declare that no experiments were performed on humans or animals for this study. 
Confidentiality of data. The authors declare that they have followed the protocols of their work center on patient data publication.

Right to privacy and informed consent. The authors have obtained the written informed consent of the patients or subjects mentioned in the article. The corresponding author has this document.

\section{Conflicts of interest}

The authors declare that they have no conflicts of interest.

\section{Funding}

None.

\section{References}

1. World Health Organization. Coronavirus Disease (COVID-19) Situation Report-158. Geneva: World Health Organization; 2019. Available from: https://www.who.int/docs/default-source/coronaviruse/situation-reports/20200626-covid-19-sitrep-158.pdf?sfvrsn=1d1aae8a_2. [Last accessed on 2020 Jun 27].

2. Gobierno de México. Corononavirus (COVID-19). Comunicado Técnico Diario COVID-19. México: Gobierno de México; 2020. Available from: https://www.gob.mx/salud/documentos/coronavirus-covid-19-comunicado-tecnico-diario-238449.

3. Buckman R. Breaking bad news: why is it still so difficult? Br Med J (Clin Res Ed). 1984;288:1597-9.

4. Bain MG, Lian CW, Thon CC. Breaking bad news of cancer diagnosis-perception of the cancer patients in a rural community in Malaysia. South Asian J Cancer. 2014;3:116-21.

5. Seifart C, Hofmann M, Bär T, Riera Knorrenschild J, Seifart U, Rief W. Breaking bad news-what patients want and what they get: evaluating the SPIKES protocol in Germany. Ann Oncol. 2014;25:707-11.

6. Fallowfield L, Jenkins V. Communicating sad, bad, and difficult news in medicine. Lancet. 2004;363:312-9.

7. Baile WF, Buckman R, Lenzi R, Glober G, Beale EA, Kudelka AP. SPIKES-A six-step protocol for delivering bad news: application to the patient with cancer. Oncologist. 2000;5:302-11.

8. Buckman R, Kason Y. How to Break Bad News: a Practical Guide for Healthcare Professionals. Toronto: University of Toronto Press; 1992.

9. Hobgood C, Harward D, Newton K, Davis W. The educational intervention "GRIEV ING" improves the death notification skills of residents. Acad Emerg Med. 2005;12:296-301.

10. Johnson J, Panagioti M. Interventions to improve the breaking of bad or difficult news by physicians, medical students, and interns/residents: a systematic review and meta-analysis. Acad Med. 2018;93:1400-12.

11. Gröning I, Biermann H, Schröder H. Überbringung Schlechter Nachrichten in Der Notfallmedizin-eine Systematische Übersicht. New York: Notfall Rettungsmed; 2020.
12. Karkowsky CE, Landsberger EJ, Bernstein PS, Dayal A, Goffman D, Madden RC, et al. Breaking bad news in obstetrics: a randomized trial of simulation followed by debriefing or lecture. J Matern Fetal Neonatal Med. 2016;29:3717-23.

13. Paul CL, Clinton-McHarg T, Sanson-Fisher RW, Douglas H, Webb G. Are we there yet? The state of the evidence base for guidelines on breaking bad news to cancer patients. Eur J Cancer. 2009;45:2960-6.

14. Parry R. COVID-19: Evidence-based Advice for Difficult Conversations. United Kingdom: Real Talk Training; 2020. Available from: https://www. realtalktraining.co.uk/app/uploads/2020/03/COVID-19-Evidence-based-advice-for-difficult-conversations-2.pdf.

15. Wolf $\mathrm{I}$, Waissengrin $\mathrm{B}$, Pelles $\mathrm{S}$. Breaking bad news via telemedicine: a new challenge at times of an epidemic. Oncologist. 2020;25:e879-80.

16. Rimmer A. How can I break bad news remotely? BMJ. 2020;369:m1876.

17. Lai J, Ma S, Wang Y, Cai Z, Hu J, Wei N, et al. Factors associated with mental health outcomes among health care workers exposed to coronavirus disease 2019. JAMA Netw Open. 2020;3:e203976.

18. Ingravallo $\mathrm{F}$. Death in the era of the COVID-19 pandemic. Lancet Public Health. 2020;5:e258.

19. Wakam GK, Montgomery JR, Biesterveld BE, Brown CS. Not dying alone-modern compassionate care in the COVID-19 pandemic. $\mathrm{N}$ Engl $\mathrm{J}$ Med. 2020;382:e88

20. World Health Organization. Requirements and Technical Specifications of Personal Protective Equipment (PPE) for the Novel Coronavirus (2019$\mathrm{nCov}$ ) in Healthcare Settings. Washington, DC: Pan American Health Organization; 2020. Available from: https://www.iris.paho.org/handle/10665.2/51977.

21. Centers for Disease Control and Prevention. Coronavirus Disease 2019 (COVID-19). Strategies to Optimize the Supply of PPE and Equipment. Washington, DC: Centers for Disease Control and Prevention; 2020. Available from: https://www.cdc.gov/coronavirus/2019-ncov/hcp/ppe-strategy/index.html.

22. Russell ME, Scott AB, Boggero IA, Carlson CR. Inclusion of a rest period in diaphragmatic breathing increases high-frequency heart rate variability: implications for behavioral therapy. Psychophysiology. 2017:54:358-65.

23. Organización Mundial de la Salud, War Trauma Foundation y Visión Mundial Internacional. Primera Ayuda Psicológica: Guía Para Trabajadores de Campo. Geneva: World Health Organization; 2012. Available from: https://www.who.int/mental health/publications/guide field workers/es.

24. International Federation of Red Cross and Red Crescent Societies. Psychosocial Centre. Remote Psychological First Aid During the COVID-19 Outbreak. Copenhagen: International Federation of Red Cross and Red Crescent Societies; 2020. Available from: https://www.pscentre.org/ wp-content/uploads/2020/03/Remote-PFA.pdf.

25. Spelten E, Thomas B, O'Meara PF, Maguire BJ, FitzGerald D, Begg SJ. Organisational interventions for preventing and minimising aggression directed towards healthcare workers by patients and patient advocates. Cochrane Database Syst Rev. 2020;4:CD012662.

26. Centers for Disease Control and Prevention. Violencia. Peligros Ocupacionales en los Hospitales. Washington, DC: Centers for Disease Control and Prevention; 2020. Available from: https://www.cdc.gov/spanish/niosh/ docs/2002-101_sp/default.html\#: :text=Para\%20prevenir\%20la\%20violencia\%20en,el\%20control\%2C\%20y\%20un\%20sistema.

27. McKay D, Heisler M, Mishori R, Catton H, Kloiber O. Attacks against healthcare personnel must stop, especially as the world fights COVID-19. Lancet. 2020;395:1743-5.

28. Toutin-Dias G, Daglius-Dias R, Scalabrini-Neto A. Breaking bad news in the emergency department: a comparative analysis among residents, patients and family members' perceptions. Eur J Emerg Med. 2018;25:71-6.

29. Gobierno de la Ciudad de México. Secretaría de Gestión Integral de Riesgos y Protección Civil. Curso en Línea: Comunicación Empática de Malas Noticias en el Contexto de COVID-19. Mexico: Secretaría de Protección Civil; 2020. Available from: https://www.educacion.proteccioncivil.cdmx.gob.mx. 